\title{
Hope when so little is left
}

Previously published at www.cmaj.ca

\section{After Her Brain Broke: Helping My \\ Daughter Recover Her Sanity \\ Susan Inman \\ Bridgeross Communications; 2010.}

A fter medical school and 30 years as a family doctor, I thought I knew a lot about serious mental illness. Then a member of my family was diagnosed with schizophrenia. I quickly learned much, much more. I wish I had had Susan Inman's book After Her Brain Broke: Helping My Daughter Recover Her Sanity as a guide.

Inman tells the story of how she and her husband struggled to understand and cope with their teenage daughter's increasingly bizarre behaviour and hostility as her diagnoses changed from "just normal teenage rebellion" to bipolar illness to schizoaffective disorder. For two years, Molly was profoundly psychotic despite hospitalizations and

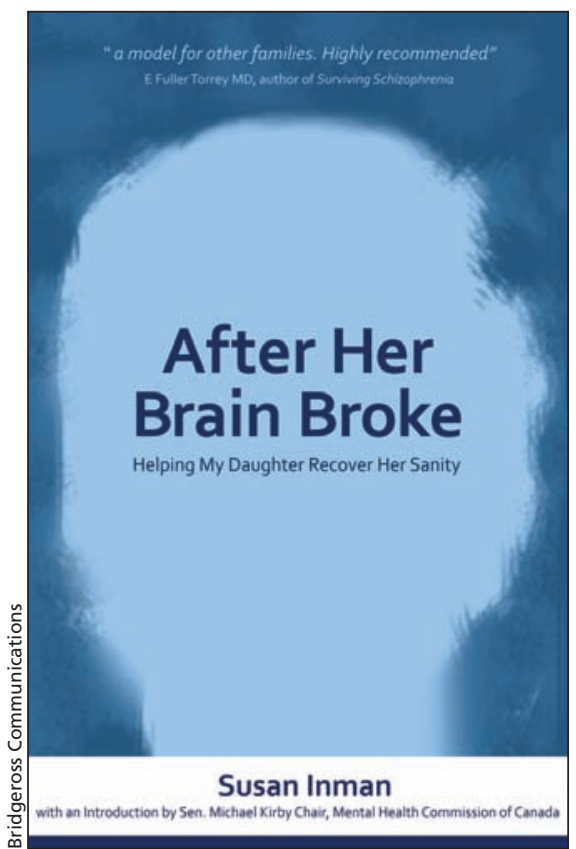

Then came "the breakthrough" when she was started on clozepine and began recovery.

One afternoon Molly is sitting in the chair in the living room where she

\section{This book is well written, moving without} being sentimental, informative without being pedantic.

many different treatments. She lost most of her cognitive functions.

"When I allow myself to picture how Molly was and how little is left of her, I wail." spends vast amounts of time rarely moving or speaking. I know I should read more about catatonia, but at this moment I am reading a soul-nurturing novel. The steadiness in Molly's voice startles me.
"My head feels so much clearer."

So many words and they haven't been coaxed out of her. She is looking at me with a firm gaze.

"My head is clearer."

I squash the hope impulse that has gotten out of hand so many times before.

"Oh. Does it feel good?"

She is still completely present.

"Yes."

Inman describes the heartbreaking struggle her family goes through as her daughter's care is managed and mismanaged. There were professionals who blamed and excluded the parents, poor advice, inadequate dosing of antipsychotic drugs and a lack of understanding of the cognitive rehabilitation needed in psychoses. She also describes the help from professionals who understood the disease and respected the family members. She found support and has been active in supporting and educating other parents of psychotic children as part of National Alliance on Mental Illness and the British Columbia Schizophrenia Society.

After Her Brain Broke is highly recommended for both physicians and family members of patients suffering from psychosis. It is well written, moving without being sentimental, informative without being pedantic. In the end, it provides hope, because we know one person who was so very sick has recovered with the help of her family and doctors.

\section{Ellen Wiebe MD}

Medical Director

Willow Women's Clinic

Vancouver, BC 